\title{
LIBERDADE E NECESSIDADE EM HOBBES: REFLEXÕES SOBRE O LIVRE ARBÍTRIO NAS ORIGENS DO ESTADO MODERNO
}

\author{
Freedom and Necessity in Hobbes: \\ Reflections on free will in the origins of the Modern State \\ Libertad y Necesidad en Hobbes: \\ Reflexiones en el libre arbitrio en los orígenes del Estado Moderno
}

Anderson Vichinkeski Teixeira'

Universidade do Vale do Rio dos Sinos, São Leopoldo, RS, Brasil.

\section{Resumo}

No presente artigo pretende-se abordar o conceito de liberdade nas principais obras de Thomas Hobbes, objetivando discutir a centralidade do manuscrito Liberdade e Necessidade para a compreensão das variações que caracterizam o pensamento hobbesiano na abordagem do referido conceito. A pouca clareza que se verifica na noção de liberdade decorre, em parte, de mudanças de convicção do filósofo quanto à possibilidade de usar de modo diferente a liberdade do indivíduo como entidade física e a liberdade do indivíduo no seio do corpo político. Todavia, será sustentado, como hipótese teórica para a presente pesquisa, que ao longo do debate com Bramhall teria sido possível a Hobbes esclarecer muitas dessas imprecisões terminológicas e variações conceituais, sobretudo no que toca a relação entre liberdade e necessidade na sua teoria das causas antecedentes.

Palavras-chave: Filosofia política. Liberdade. Necessidade. Hobbes. Bramhall.

\footnotetext{
Doutor em Filosofia do Direito pela Universidade de Florença/IT. Professor do Programa de Pós-Graduação em Direito da Universidade do Vale do Rio dos Sinos (UNISINOS). ORCID: orcid. org/0000-0001-7085-0375. E-mail: andersonvteixeira@hotmail.com
} 


\begin{abstract}
In this article we intend to deal with the concept of freedom in the main works of Thomas Hobbes, aiming to discuss the centrality of the manuscript Of Liberty and Necessity for the understanding of the variations that characterized the Hobbesian thought in the approach of the abovementioned concept. The lack of clarity in the notion of liberty seems to be, in part, a consequence of the changes in the philosopher's conviction about the possibility of using the freedom of the individual as a physical entity in a different way of the freedom of the individual within the political body. However, it will be argued, as a theoretical hypothesis for this research, that during the debate with Bramhall it would have been possible for Hobbes to clarify many of these terminological imprecisions and conceptual variations, especially in relation to freedom and necessity in his theory of antecedents causes.
\end{abstract}

Keywords: Political philosophy. Liberty. Necessity. Hobbes. Bramhall.

\title{
Resumen
}

Este artículo pretende abordar el concepto de libertad en las principales obras de Thomas Hobbes, con el objetivo de discutir la centralidad del manuscrito la Libertad y la Necesidad para se entender las variaciones que caracterizan el pensamiento hobbesiano sobre el referido concepto. La poca claridad que se verifica en la noción de libertad se deriva en parte, de los cambios en la convicción del filósofo con respecto a la posibilidad de utilizar de manera diferente la libertad del individuo como entidad física y la libertad del individuo dentro del cuerpo político. Sin embargo, se sostendrá, como hipótesis teórica para esta investigación, que durante el debate con Bramhall habría sido posible que Hobbes aclarara muchas de estas inexactitudes terminológicas y variaciones conceptuales, especialmente en relación con la relación entre Libertad y necesidad en su teoría de causas antecedentes.

Palabras clave: Filosofía política. Libertad. Necesidad. Hobbes. Bramhall.

\section{Introdução}

Considerado um dos grandes filósofos da Modernidade, Thomas Hobbes (1588-1679) possui uma vasta obra que cobre diversos campos do saber, desde a ética até a política, desde a filosofia até temas caros à ciência política, sobretudo no que concerne os regimes políticos e sua 
notória crítica a Aristóteles. Diferentemente de filósofos políticos dos séculos XVI e XVII, Hobbes demonstrou singular capacidade em atribuir cientificidade analítica aos seus objetos de estudo, tornando-se amplamente reconhecido pelo modo coerente como sistematizou suas ideias e análises - não fora, certamente, sua preferência pela monarquia o grande legado deixado para a filosofia e as ciências humanas em geral!

Não obstante essas suas características epistemológicas típicas de um verdadeiro cientista do saber, o pensamento hobbesiano é marcado pela abordagem cambiante acerca de um determinado conceito: a liberdade. Um dos pontos controvertidos é o modo como ocorre a relação entre a liberdade do indivíduo/súdito e o poder do Soberano; esta relação poderia ser prima facie suposta como de conflito, mas Hobbes encontra uma forma de conciliá-la. Ao longo das suas principais obras, Hobbes utilizou conceitos de liberdade variados, de pouca clareza e, em certa medida, com algum grau de incongruência em relação a sua própria doutrina. Já houve até quem (PENNOCK, 1960), com perspicácia, denominasse "confunsing clarity" o caso da liberdade no pensamento hobbesiano.

Objetivando oferecer ao leitor as melhores e mais acessíveis fontes de pesquisa atualmente no Brasil, a análise do conceito de liberdade em Hobbes seguirá a ordem cronológica das suas principais publicações concernentes a tal objeto de estudo: Elementos da Lei Natural e Política (1640), Do Cidadão (1642), Liberdade e Necessidade (1646? - ver, no item específico infra, polêmica acerca da data precisa e as razões pelas quais foi adotada aqui a edição francesa organizada por Franck Lessay) e Leviatã (1651).

O objetivo geral do presente artigo é demonstrar a centralidade da obra Liberdade e necessidade para a compreensão das oscilações conceituais que caracterizam o pensamento hobbesiano. A pouca clareza que se verifica na noção de liberdade decorre, em parte, das mudanças de convicção quanto à possibilidade de usar de modo diferente a liberdade do indivíduo como entidade física e a liberdade do indivíduo no seio do corpo político, i.e., sob a égide de mandamentos morais e jurídicos. Quando elaborou seu livro Elementos da Lei Natural e Política, Hobbes claramente concebeu a liberdade 
em uma perspectiva simples que tomava o pacto social como um momento conceitual divisor entre a condição natural de plena ausência de constrições e a condição de submissão às constrições de um Estado instituído. Em seu Do Cidadão, a questão torna-se mais complexa e os impedimentos arbitrários ganham grande relevância. Já o Leviatã é tido como o ponto máximo de desenvolvimento do conceito em tela, pois nessa obra Hobbes diferencia a liberdade do indivíduo da liberdade do Soberano, ainda que sem enfrentar claramente as variações que o problema da liberdade deixara em suas obras anteriores. Entretanto, em Liberdade e necessidade há um enfrentamento do autor quanto a grande parte das imprecisões apresentadas ao longo das obras precedentes, tendo em vista que o embate teórico com o bispo John Bramhall tinha como ponto central o livre arbítrio do ser humano.

\section{0 conceito de liberdade no Elementos da Lei Natural e Política}

Ainda não foi nessa obra que o conceito de liberdade seria considerado em si, i.e., na sua vinculação com a ausência de impedimentos externos e impedimentos arbitrários, pois o objetivo primeiro do autor é distinguir o indivíduo natural do indivíduo no corpo político. Com isso, é no Cap. XII da Parte I, intitulado "Como, por deliberação das paixões, procedem as ações dos homens", que Hobbes trata da liberdade dentro da discussão sobre vontade, fundando as bases para a discussão sobre o estado de natureza e sobre a transição ao corpo político (Parte II).

O citado capítulo inicia com a tentativa de recuperar a demonstração feita em precedência de que os objetos externos causam no indivíduo duas opostas reações psíquicas: o apetite e o medo. As ações humanas formariam uma sucessão de procedimentos baseados no apetite e no medo, de modo que "[E]ssa sucessão alterada entre o apetite e o medo durante todo o tempo em que temos em nosso poder a ação para fazê-la ou não fazê-la é o que chamamos deliberação" (HOBBES, 2002, p. 84). Logo, o primeiro passo para a compreensão da vontade seria verificar se 
uma ação ou omissão fora precedida de uma deliberação, ainda que os atos improvisados ou impulsivos sejam considerados como consequências de um processo movido pelo apetite ou pelo medo. A escolha que leva a uma ação está assentada em uma deliberação consequente da racionalização de quais meios são os corretos para que seja alcançado o fim. No entanto, Hobbes sustenta que o processo deliberativo é próprio de cada indivíduo, pois a deliberação em si representa uma manifestação da vontade livre, enquanto que: "O apetite, o medo, a esperança e as demais paixões não são chamadas voluntárias, pois elas procedem não da vontade, mas são vontade; e a vontade não é voluntária" (HOBBES, 2002, p. 84). Em toda sua obra esse pode ser entendido como o momento germinal para a análise do confronto entre liberdade e obrigações políticas, uma vez que a questão da vontade assume destaque na manutenção do livre arbítrio dentro de um Estado instituído, i.e., em face do Soberano.

A definição de vontade não ocorre com base naquilo que a torna possível, ou seja, a deliberação, mas sim a partir do resultado que um ato voluntário necessitaria para consolidar-se verdadeiramente como tal. Tendo em vista que, para Hobbes (2002, p. 84), "é a mesma coisa dizer vontade e vontade última", não seria incorreto afirmar que as suas considerações sobre a vontade servem para tornar irreversível o próprio pacto. Ele assim funda as bases para que o contrato social seja um ato voluntário em condições de encerrar a discussão acerca de fazer ou não fazer consequente da liberdade absoluta existente no estado de natureza. Nos Elementos o pacto é uma espécie do gênero do contrato, onde existe a promessa de execução futura por ambas as partes. A não execução - e, consequentemente, o rompimento do pacto - deveria ser entendida, segundo Hobbes (2002, p. 108), como injúria (injury) e representaria uma contradição com a máxima pacta sunt servanda, já que aquele que faz um pacto deseja expressamente fazer, ou deixar de fazer, no futuro, e aquele que executa uma ação a deseja naquele presente, que é parte do futuro contido no pacto anterior; com isso, aquele que viola o pacto deseja a execução, ou não, da mesma coisa no mesmo tempo previsto quando da feitura do pacto. 
A celebração de um pacto importa na manifestação da vontade livre e na restrição à liberdade anterior ao pacto, pois representa o início de um processo contínuo e irreversível de alternância entre apetites e medos, mediados pela deliberação, que culmina na contemporaneidade do momento de realização do pacto. Em Do Cidadão, quando ocorre a distinção entre obrigar-se ao pacto e ser obrigado por uma lei, Hobbes (1998, p. 216-218) não retoma o mesmo nível de profundidade da sua análise da formação da vontade no Elementos. Em ambas obras o pacto e a lei são tratados de maneiras distintas, pois ao celebrar um pacto o indivíduo se auto-obriga, enquanto que em face da lei ele assume uma obrigação externa a sua própria vontade. Em Do Cidadão está claro que tanto o pacto quanto a lei possuem um caráter obrigatório para as partes, retirando destas a possibilidade de alteração ulterior. Ademais, o nível de obrigatoriedade da lei variará quando se tratar da lei positiva, da lei natural ou da divina. O pacto que instituiu o Estado Soberano necessita de legislação especificando a promessa genérica contida nele, sob pena de não se tornar efetivo no plano fático. Assim, a complementaridade existente entre o pacto e a lei positiva manifesta-se como consequência lógico-racional da relação entre ambos.

Junto com essa especificação do pacto encontra-se presente a função coercitiva da lei positiva, decorrente da vontade do Soberano de criar um temor às penas. Ao vincular os temores à pena na sua doutrina das obrigações, Hobbes se impõe uma objeção: se é possível sustentar que com o pacto o indivíduo se empenha em querer para o seu futuro aquilo que desejaria para outrem, então seria possível aceitar que o indivíduo tenha condições de determinar livremente sua própria vontade; ocorre que esta possibilidade Hobbes nega veementemente, dizendo que somente as ações podem ser consideradas voluntárias, não a vontade. Hobbes (2002, p. 132) usa a noção de temor para tentar responder a esta dificuldade terminológica acerca da vontade livre em um Estado instituído, afirmando que o indivíduo que pactua está se sujeitando, por meio da vontade, ao comando de outro indivíduo, este que poderá valer-se da força para tornar efetivo o pacto, pois deve constringir a vontade de todos à unidade e à concórdia recíproca. 
A instituição do Estado é um momento divisor para a noção de liberdade no Elementos. Hobbes (2002, p. 131-132) acredita que o consenso instituidor do contrato social limita as diversas situações que poderiam impedir a afirmação e o desenvolvimento da vontade coletiva personificada na figura do Soberano: a vontade deste equivale à vontade de todos, devendo substituir a vontade do indivíduo, em decorrência da conjunção de vontades ocorrida quando da formulação do pacto.

A noção de liberdade empregada por Hobbes no Elementos estava implícita como pressuposto para a dissociação operada por ele entre vontade voluntária e vontade não voluntária. A necessidade - problema que no debate com o bispo Bramhall será o fulcral - é algo que surge nos Elementos apenas para resolver o conflito aparente existente na execução de atos contrários à vontade. $\mathrm{A}$ irreversibilidade dos atos voluntários resta como elemento teórico de grande importância para sua construção teórica do Soberano.

\section{As espécies de liberdade em Do Cidadão}

Essa obra possui um grande significado para o estudo da noção de liberdade em Hobbes, sobretudo porque a Parte I já ganha o expressivo título de "Liberdade". É nesta parte que ele propõe uma divisão do referido conceito em três espécies: a liberdade como pressuposto para a deliberação; a liberdade como ausência de impedimentos externos; e a liberdade como ausência de impedimentos arbitrários.

O primeiro tipo de liberdade é ilustrado por Hobbes (1998, p. 41-42) na diferença entre alguém que faz uma doação e aquele que pactua: enquanto o primeiro mantém sua liberdade, o segundo sofre algum grau de perda de liberdade. $O$ exemplo é meramente ilustrativo da condição do livre arbítrio nesta espécie de liberdade: trata-se de um pressuposto subjetivo que permite ao indivíduo deliberar. $O$ resultado útil do processo deliberativo, i.e., a escolha confirmada mediante a ação objetiva, terá o condão de encerrar aquela condição particular de liberdade para a deliberação que moveu o indivíduo naquele momento específico em relação àquela decisão 
específica. A preocupação com a não contradição, muito característica nos Elementos, está novamente presente para sustentar que o indivíduo que se empenha pelo futuro de uma ação deseja que esta venha a se realizar, mas se não a fizer significa que desejou e não desejou ao mesmo tempo, o que demonstra uma aparente contradição. Em outras palavras, nesta obra está incorporada como uma espécie de liberdade aquela presente nos Elementos.

Já a segunda espécie aparece pela primeira vez em Do Cidadão: a liberdade como ausência de impedimentos externos. Hobbes (1998, p. 149) diz que:

[A] liberdade, podemos assim a definir, nada mais é que ausência dos impedimentos e obstáculos ao movimento; portanto, a água represada num vaso não está em liberdade, porque o vaso a impede de escoar; quebrado o vaso, ela é libertada.

Assim, ao utilizar uma metáfora com objetos físicos, Hobbes associa impedimentos externos a obstáculos ao movimento.

Na obra em comento, o autor retoma a sua construção acerca da vontade como elemento impeditivo para sucessivas deliberações, pois o pacto celebrado é obrigatório pelo fato de ser voluntário. Todavia, ganha maior importância neste momento um argumento que nos Elementos era secundário: o temor como algo pelo qual o indivíduo está vinculado às suas escolhas. Deste modo, o temor passa a ser entendido como um particular tipo de impedimento, diverso dos anteriormente vistos, uma vez que se constitui em um impedimento arbitrário, que não barra a execução de uma ação, mas que atribui ao resultado efeitos desagradáveis para o indivíduo. Não é apenas um fato da natureza, como um obstáculo ao movimento, que poderá ensejar medo no indivíduo, mas também um elemento subjetivo terá essa capacidade, como o medo da sanção decorrente do descumprimento de uma norma.

Ao introduzir a noção de impedimento arbitrário, Hobbes enquadra nessa todas as situações em que o indivíduo, mesmo sendo livre de impedimentos externos, decide não executar uma ação por medo dos seus efeitos, sejam eles físicos, naturais ou necessários. No entanto, existem 
circunstâncias psicofísicas onde o indivíduo pode consentir com uma ação, ao invés de manter-se omisso. $O$ caso do suicídio representa bem essa situação. $\mathrm{O}$ ato de pular de um castelo ou de uma ponte nada mais é do que um mero passo que não encontra impedimentos externos, apenas o temor. O suicida, aquele que deu o passo que o indivíduo mentalmente saudável jamais daria, usufruiu de um grau de liberdade maior do que aqueles que não deram o passo. As leis da natureza, as quais determinam a abstenção a certos atos para que seja possível a manutenção da vida, não representam qualquer impedimento para o suicida, pois esse perdeu o senso de autopreservação, escopo maior de todos os animais.

O exemplo do suicida demonstra que a liberdade do indivíduo está, invariavelmente, submetida a algum grau de restrição. Recorde-se que a primeira lei natural prescreve o dever de buscar a manutenção da própria vida, constituindo, assim, um impedimento interno. A reta razão impõe ao indivíduo o impulso de nunca aceitar a morte sem tentar fugir dela, mesmo que a morte, ou outra sevícia, seja uma consequência do inadimplemento do que fora pactuado.

Ainda que nos Elementos a teoria das obrigações naturais tenha sido concentrada na Parte I, dedicado ao estudo do indivíduo natural, Hobbes (1998, p. 53) agora vincula os deveres decorrentes do pacto como obrigações naturais necessárias para a manutenção da paz e da concórdia recíprocas. Todavia, o temor da morte age sobre a vontade como se fosse um em meio aos demais medos e apetites. Tomando por base o fato de terem uma validade universal, Hobbes estende o mesmo raciocínio a todos os temores e esperanças vinculados à noção de impedimento arbitrário. A liberdade que certos temores e esperanças tolhem é a possibilidade que um indivíduo mentalmente sadio possa agir contrariamente ao demandado pelas paixões. É a universalidade subjetiva do conhecimento do êxito de algumas paixões que determina a vontade, de modo que não é razoável para o indivíduo, por causa de sua fraqueza, agir contra algo que lhe é superior em força e poder.

Hobbes (1998, p. 218-220) diferencia duas espécies de obrigações naturais: a primeira ocorre quando a liberdade encontra-se sem impedimentos 
físicos; a segunda espécie ocorre quando a vontade do indivíduo está submetida a algum mandamento capaz de lhe provocar apetite ou medo. Esta segunda forma de obrigação natural possui a capacidade de impor coerção psicológica e limitar a capacidade de resistência do indivíduo, uma vez que ele está submetido a algo maior, como à onipotência divina. Já o primeiro tipo de obrigação natural considera as leis naturais como delimitadores do exercício da liberdade, pois a não obediência a elas importa em prejuízos para o ofensor; o domínio cognitivo-intelectual do indivíduo quanto aos impedimentos físicos é o que Ihe possibilita, por exemplo, o desenvolvimento de técnicas de cultivo e produção de alimentos, adestramento de animais etc. Ainda que em proporções diferentes, do mesmo modo pelo qual as leis da natureza instauraram uma relação de obediência do indivíduo perante a Deus, elas criaram uma relação de sujeição entre o súdito e o Soberano, tendo em vista a universalidade das leis naturais (HOBBES, 1998, p. 244-245).

Por fim, o terceiro tipo é a liberdade de que gozam os cidadãos: ausência de impedimentos arbitrários. Consiste no fato de que ninguém, súdito ou servo, está impedido por causa da ameaça de penas do Estado ou do patrão, no caso do servo, de fazer tudo que for necessário para a manutenção da própria vida e saúde (HOBBES, 1998, p. 149). No entanto, a limitação da liberdade dos súditos na relação com o Soberano não significa a ausência de liberdade no uso dos direitos naturais por parte do indivíduo, uma vez que o Soberano fora instituído com base em um pacto, i.e., um ato deliberado pela vontade racional cujos efeitos obrigam todos os súditos. Logo, o temor é elemento determinante da vontade porque elimina possibilidades de escolhas, sobretudo por se encontrar racionalizado por intermédio das próprias leis instituídas pelo Estado na busca da conservação do pacto original, justificando a impossibilidade de rompimento do pacto e descumprimento das leis. Não obstante outros temores possam suscitar paixões violentas, como a morte, Hobbes concentra suas atenções em obrigações decorrentes do pacto como instrumentos pelos quais o próprio pacto deverá ser respeitado, uma vez que a liberdade natural fora abdicada no momento de instituição do Soberano. 
Inegavelmente, Do Cidadão é a obra com maior variedade de sentidos possíveis para a noção de liberdade em Hobbes. Por uma questão metodológica, a próxima obra em exame será o Leviatã, permitindo que, ao final do presente artigo, a controvérsia que ensejou o Liberdade e Necessidade possa ser enfrentada.

\section{Leviatã e a consagração da liberdade do Estado}

Notoriamente reconhecido como seu opus magnum, o Leviatã congrega diversas concepções desenvolvidas por Hobbes até então, formando seu grande tratado de filosofia política. Muitas das críticas feitas a obras precedentes, sobretudo ao Do Cidadão, encontraram refutações ou esclarecimentos no texto de 1651 . Importante destacar que quando da elaboração deste livro a controvérsia com o bispo Bramhall já estava em curso havia cinco anos, se considerarmos o momento em que teriam se conhecido na casa parisiense do Marquês de Newcastle.

No que concerne ao conceito de liberdade, na obra em questão Hobbes dedica a este tema um tópico específico do Capítulo XIV, logo após tratar no capítulo precedente do estado de natureza. O título do tópico é expressivo por si só: "O que é Liberdade?" ("Liberty what?") Neste momento, o objetivo é concentrar suas atenções na ausência de impedimentos do indivíduo durante o exercício de sua vontade livre. Define liberdade como "a ausência de impedimentos externos, que muitas vezes tiram parte do poder que cada um tem de fazer o que quer, mas não podem proibir a que use o poder que Ihe resta, conforme o que seu julgamento e razão lhe ditarem" (HOBBES, 1968, p. 189, tradução nossa) ${ }^{2}$. Trata-se de um esforço teórico no sentido de vincular a liberdade, por um lado, à ausência de impedimentos externos, enquanto que, por outro lado, ela estaria limitada pela deliberação. No

\footnotetext{
2 Do original: the absence of externall Impediments: which Impediments, may oft take away part of a mans power to do what hee would; but cannot hinder him from using the power left him, according to his judgement, and reason shall dictate to him.
} 
Capítulo Vl, ao tratar dos "movimentos voluntários comumente chamados paixões", Hobbes (1968, p. 127, tradução nossa) define deliberação como aquilo que tem condições de "pôr fim à liberdade que tínhamos de praticar ou evitar a ação, de conformidade com nosso apetite ou aversão."3 Em outras palavras, até o momento da deliberação o indivíduo possuía a liberdade de agir ou se omitir, de acordo com seu apetite ou aversão.

Essa é uma definição inicial, pré-societária e pré-estatal, i.e., ainda tomando o indivíduo na sua condição anterior à celebração do contrato social, mas que em Hobbes tem a clareza de agregar aos conceitos de liberdade precedentemente postos em Elementos e Do Cidadão a questão de ser a ação livre "segundo nosso apetite ou aversão". Assim, a definição de liberdade adotada no Cap. VI do Leviatã mostra-se compatível com aquela baseada na ausência de impedimentos externos do Cap. XIV.

Yves-Charles Zarka ressalta que para a teoria política hobbesiana era fundamental resolver o problema que o próprio Hobbes havia posto: como vincular o indivíduo e sua livre vontade ao Estado instituído e sua respectiva vontade soberana? Zarka (2001, p. 61) recorda que a resposta de Hobbes foi conceber o corpo político como síntese da vontade de todos os particulares. Com isso, é reforçada e maximizada a tese de que a violação do pacto implicaria em uma contradição: o pacto era o produto de uma deliberação, esta que era o produto da "vontade livre" de cada indivíduo, esta que era guiada pelas "paixões naturais" sob o filtro da reta razão.

Estando posta em cena uma cadeia de relações de causa e efeito decorrentes, racionalmente, umas das outras, o indivíduo hobbesiano será livre para fazer aquilo que desejar fazer, segundo seu apetite ou aversão; todavia, sua liberdade de ação encontrará limites, primeiro, nos impedimentos externos, em seguida, nos impedimentos arbitrários e, por fim, na irreversibilidade da vontade voluntariamente expressa em um pacto. A compreensão do conceito de liberdade surge como ausência de

3 Do original: putting an end to the Liberty we had of doing, or omitting, according to our own Appetite, or Aversion. 
impedimentos externos, na obra em questão, quando o autor trata, no Cap. XIV, das leis naturais, mas também no momento de abordar a liberdade dos súditos, no Cap. XXI. Ocorre uma transição, então, da abordagem da liberdade no estado de natureza para a liberdade no Estado Soberano.

No Capítulo XXI do Leviatã, intitulado “Da liberdade dos súditos”, já na primeira frase é recuperada, de modo genérico, a definição de liberdade como "ausência de oposição entendendo por oposição os impedimentos externos ao movimento. Não se aplica menos às criaturas irracionais e inanimadas do que às racionais" (HOBBES, 1968, p. 261, tradução nos$\mathrm{sa})^{4}$. Mantendo-se coerente com o que já havia escrito em outras obras precedentes, Hobbes afirma que o único sentido em que se pode falar de liberdade dos súditos é sob a perspectiva da licitude: "A liberdade dos súditos, portanto, está apenas naquelas coisas que, ao regular suas ações, o Soberano permitiu" (HOBBES, 1968, p. 264, tradução nossa) ${ }^{5}$. Existem então domínios da vida nos quais não compete ao Soberano decidir em nome do súdito, como onde morar, com quem se casar, onde trabalhar etc. Em um Estado instituído, o súdito teria direito não do mesmo modo como ocorre com a liberdade, i.e., em decorrência da ausência de impedimentos externos: o seu direito seria consequência da ausência de um comando ou proibição que se oponha ao seu próprio livre arbítrio.

No Leviatã a ruptura aparente entre estado de natureza e Estado instituído é superada, pontualmente, pela associação que se verifica entre liberdade e ter direito. Enquanto a liberdade segue um processo de especialização em condições de enfrentar as diversas possibilidades para a manifestação da vontade humana, o direito segue um rumo distante: do direito absoluto a tudo que o indivíduo possuía em estado de natureza, inverte-se a lógica e ele passa a ter direitos somente com base na norma

\footnotetext{
4 Do original: the absence of Opposition (by Opposition, I mean externall Impediments of motion;) and may be applyed no lesse to Irrationall, and Inanimate creatures, than to Rationall.

5 Do original: The Liberty of a Subject, lyeth therefore only in those things, which in regulating their actions, the Sovereign hath praetermitted.
} 
posta pelo Soberano. O direito surge, então, sob a forma de licitude positiva. Ocorre a transferência da liberdade absoluta que o indivíduo possuía antes do pacto, i.e., antes da Autorização (Cap. XVIII, do Leviatã), para o Soberano que receberá a prerrogativa de uso desse direito absoluto a tudo, mas agora tendo como objetivo a paz e concórdia recíprocas em proveito da manutenção da vida de cada um que lhe autorizou.

Ainda no Cap. XXI, resta claro que o conceito elementar de liberdade em toda e qualquer sociedade civil organizada não é a liberdade dos indivíduos, mas a liberdade do Estado (HOBBES, 1968, p. 265). Trata-se da autorização dada por cada indivíduo, por meio do pacto, para que aquele direito a tudo que cada um possuía em estado de natureza, i.e., a plena liberdade individual que caracterizava a condição natural de cada indivíduo antes da instituição do Estado, passe a ser então prerrogativa exclusiva deste, restando ao indivíduo uma espécie de liberdade residual para fazer aquilo que o Soberano permite, por meio de suas leis, ou simplesmente tolera, por meio do seu silêncio legislativo.

Há no Leviatã, no citado capítulo, uma passagem que parece ser uma resposta direta ao bispo Bramhall: "Liberdade e Necessidade são Compatíveis" (HOBBES, 1968, p. 263). Segue afirmando que, embora os homens possam fazer muitas coisas que Deus não ordenou, e das quais, portanto, não é autor, não lhes é possível "ter paixão ou apetite por nada cujo apetite a vontade de Deus não seja a causa" (HOBBES, 1968, p. 264, tradução nossa). ${ }^{6}$ São cerca de duas páginas destinadas a enfrentar o modo como a contingência de um ato produto de uma necessidade - como o exemplo que cita das águas que escorrem pelo canal não apenas por terem a liberdade de se mover, mas também em virtude da necessidade de seguir o sentido do canal - diferencia-se da liberdade intrínseca a um ato da vontade livre. Porém, a análise deste tema poderá ser mais bem enfrentada no próximo e último item.

6 Do original: have no passion, nor appetite to any thing, of which appetite Gods will is not the cause. 


\section{A controvérsia com o bispo Bramhall em Liberdade e Necessidade}

Não obstante tenha sido pouco explorado pela doutrina, sobretudo de língua portuguesa ${ }^{7}$, trata-se de um debate altamente polêmico e que se alongou por anos. A polêmica é tanta que mesmo a origem da primeira resposta de Hobbes, intitulada "Of Liberty and Necessity", nunca foi claramente precisada em sua data. Uma advertência inicial deve ser feita: o manuscrito que se encontra, atualmente, na British Library, feito por um copiador desconhecido, é o único que ainda pode ser considerado original da época de Hobbes. Franck Lessay (1993, p. 40-42), organizador e tradutor da versão francesa, publicada pela editora Vrin, utilizou o referido manuscrito para a tradução que está servindo de base de pesquisa ao presente artigo. As outras duas traduções existentes (italiano e espanhol) valeram-se de uma versão editada por William Molesworth, em 1840, mas que possui diversas notas de rodapé e citações bíblicas acrescidas pelo editor britânico (LESSAY, 1993, p. 49).

Retornando à polêmica acerca da data, Bramhall era conhecido por ser meticuloso e detalhista; foi dele a indicação de que 20 de agosto de 1645 teria sido a data em que Hobbes assinara o manuscrito. Ambos se conheceram por intermédio de um amigo em comum, Marquês de Newcastle, no mesmo ano de 1645, durante o exílio de Hobbes em Paris. A Primeira Guerra Civil britânica (1642-1646) levara Hobbes ao exílio, assim como Bramhall. Todos os três eram apoiadores do sistema monárquico à época em crise na ilha. Fato curioso, bem lembrado por Leibniz (1842, p. 319), é que Hobbes e Bramhall não pretendiam publicar seus respectivos textos, sobretudo porque cada texto vinha endereçado ao amigo em comum, Marquês de Newcastle, sempre em um formato de refutação recíproca entre ambos, carecendo de uma melhor estruturação. Teria sido um amigo francês de Hobbes o responsável por levar o texto "Of Liberty and Necessity" a um jovem que faria a versão em francês que veio a ser publicada, ao que tudo

\footnotetext{
7 Importante referir, para futuras pesquisas, as traduções de partes dos originais que constam na pesquisa de Sérgio Miranda (2011). Ver, ainda, Frateschi (2007).
} 
indicada, sem a autorização de Hobbes (LEIBINIZ, 1842, p. 319). Indignado, Bramhall publicou, em 1655, "A Defence of True Liberty from Antecedent and Extrinsical Necessity", e, em 1658, "Castigation of Mr. Hobbes". Somente ao texto de 1655 Hobbes respondeu com "The Questions concerning Liberty, Necessity, and Chance", publicado no ano seguinte.

A polêmica entre os dois - um filósofo e um teólogo de sólida formação - tinha como ponto central, em suma, a crítica de Bramhall à teoria hobbesiana das necessidades naturais e absolutas. O determinismo hobbesiano, que aceita elementos externos e antecedentes como condicionantes à vontade livre humana, era algo que o libertarianismo de Bramhall (1999, p. 1-2) não aceitava, pois, segundo esse, necessidade e liberdade seriam incompatíveis; a ação humana não poderia ser condicionada pela necessidade de um elemento externo à vontade.

Há uma marca que permeia todo o pensamento hobbesiano: a possibilidade de reduzir todas as coisas, incluindo o ser humano, à condição de objeto de estudo, mediante o método decompositivo, chamado de método more geometrico, notabilizado com Galileu, uma vez que permitia buscar as relações causais que deram efeito a determinado resultado. Simone GoyardFabre (1975, p. 20-22) destaca que Hobbes fora muito influenciado pelas conquistas da ciência moderna que tentavam atribuir padrões racionais à observação experimental das relações causais entre os seres. Ao redigir o texto de 1645 , Hobbes torna a falar sobre a questão da deliberação como uma necessidade lógica para que se possa tratar da vontade. Inicialmente, é possível afirmar que ele não exigia tanto a presença atual quanto a presunção de uma deliberação passada, pois teria sido com base em uma suposta deliberação que ações impulsivas seriam formadas. Resolvia-se, assim, o problema acerca de fazer coincidir, no plano teórico, a deliberação e a vontade, pois ações impulsivas, como se defender de um golpe brusco e inesperado, importam em uma deliberação antecedente, ainda que, ao se defender, o agente não objetive causar um resultado específico no seu ofensor.

A réplica de Hobbes às críticas de Bramhall ao seu Do Cidadão - considerando que sequer um título o bispo havia atribuído ao seu manuscrito, 
o texto tornou-se conhecido apenas como "Discurso sobre a liberdade e necessidade" - foi estruturada com o escopo inicial de refutar dois tipos de argumentos: aqueles baseados nas Escrituras e aqueles baseados na Razão (HOBBES, 1993, p. 55). Há uma espécie de primeiro pressuposto teórico geral, em condições de enfrentar os dois tipos de críticas, utilizado por Hobbes neste texto de 1645: a equiparação entre eleição e escolha, o que possibilitaria uma ação voluntária ser precedida de deliberação, i.e., de uma eleição, na mesma medida em que uma ação involuntária teria também algum tipo de eleição em seu processo intelectivo-formativo. Com isso, não subsistiria mais a distinção entre atos voluntários não precedidos por uma escolha, nos quais os indeterministas entendiam existir apenas uma necessidade, e atos voluntários provenientes de uma escolha, nos quais a vontade livre seria expressa por meio da escolha.

Há um segundo e importante pressuposto teórico geral que Hobbes (1993, p. 59) apresenta já no início de sua refutação às críticas de Bramhall: a compatibilidade entre eleição e necessidade. Ele traz referências à Bíblia, especificamente aos Livros de Josué, XXIV, 15, e Samuel, XXIV, 2, onde estaria claramente comprovado que o homem goza de capacidade de "eleição", mas não de modo amplo e irrestrito, pois suas crenças e esperanças, as ideias de Bem e de Mal, formariam considerações "necessárias" à eleição; logo, é possível que alguém escolha fazer uma coisa e, igualmente, não possa fazer outra coisa, comprovando que eleição e necessidade coexistem. Na mesma passagem Hobbes ainda usa como exemplo as ações de uma criança, de um louco e de uma besta, as quais são determinadas pelo sentido único da necessidade imposta por seus apetites e aversões, não existindo eleição, nem agentes livres.

Como visto nas demais obras do autor, a alternância entre aversões e apetites ganha o nome de deliberação. Todavia, agora Hobbes enfrenta uma crítica pontual de Bramhall que havia escancarado uma imprecisão teórica existente nas obras precedentes daquele: qual seria o lugar da espontaneidade no processo volitivo? Bramhall (1999, p. 2) entendia que as ações espontâneas não são voluntárias e não passaram por uma 
deliberação. Hobbes (1993, p. 60-61) recorda o exemplo de alguém que doa dinheiro do próprio bolso para um desconhecido como forma de ato espontâneo; entretanto, sua refutação nesse momento não é especificamente ao argumento em si do bispo, pois aqui existiria um consenso no sentido de que ações espontâneas não são voluntárias como produto de uma deliberação, mas tem o claro objetivo de demonstrar a incoerência da crítica de Bramhall em um ponto central: a sua concepção de ação espontânea permitiria a coexistência entre necessidade e eleição!

Outra crítica do bispo é decorrência da sua concepção de causas da ação:

Se o decreto de Deus ou a presciência de Deus ou a influência das estrelas ou a concatenação de causas ou a eficácia física ou moral dos objetos ou o último ditame do entendimento realmente tiram a verdadeira liberdade, então Adão antes de sua queda não teve verdadeira liberdade (BRAMHALL, 1999, p. 3, tradução nossa) ${ }^{8}$.

Segue afirmando que, uma vez que Adão fora o primeiro homem quando da Criação, não haveria sentido algum supor que esses impedimentos afastariam a verdadeira liberdade que ele possuía. É neste momento que Hobbes (1993, p. 64) retoma com clareza a sua teoria das causas anteriores ao afirmar que o que necessita e determina cada ação é a soma de todas as coisas que, existindo conjuntamente, conduzem e concorrem para a produção da ação em si; esse "concurso de causas", por meio do qual uma causa atual é determinada por outra anterior, poderia trazer mesmo o metafísico e transcendente decreto de Deus como uma causa anterior à ação humana. Ele ressalta que, se a "pré-ciência" de Deus (prescience de Dieu) é a causa de algo que não pode ser verdadeiramente dito, se tal pré-ciência está no domínio do conhecimento, um número incalculável de cadeias de

8 Do original: If the decree of God or the foreknowledge of God or the influence of the stars or the concatenation of causes or the physical or moral efficacy of objects or the last dictate of the understanding do take away true liberty, then Adam before his fall had no true liberty. 
eventos interligadas entre si por relações de causa e efeito encontrará em Deus - cognoscível na medida de um pressuposto dado, de um elemento pré-ciente do conhecimento humano - como a primeira argola a unir toda essa cadeia incalculável de eventos. (HOBBES, 1993, p. 64-65)

Existem outros pontos, de menor relevância, que Hobbes utiliza para refutar Bramhall naquilo que aquele havia denominado "argumentos baseados nas Escrituras", mas essa última análise atinente ao concurso de causas anteriores possui uma solidez argumentativa em condições de, por um lado, recuperar a celebérrima dúvida de Descartes (2016) e, por outro, reconstruí-la e recolocá-la em um novo patamar: como pressuposto do seu determinismo filosófico.

A segunda parte das refutações de Hobbes (1993, p. 73) está vinculada ao que ele denominou de "argumentos tirados da Razão". Nesse momento surge uma divisão fundamental e singularmente original na história do Estado moderno: leis injustas e ações injustas. O pensamento medieval fora caracterizado por uma sujeição da ação humana às leis em diversos níveis de transcendência, de modo que, em primeiro lugar, estaria a lei divina, em seguida, a lei moral, em terceiro lugar, a lei positiva, ordenando as ações humanas na civitas terrena. A proposta teórica de Hobbes diferencia-se dessa tradição ao estabelecer que a necessidade de uma ação não torna injusta a lei que a proíbe; não é a necessidade, mas a vontade de ofender a lei que torna a ação injusta, pois a lei busca regular a ação humana, não suas causas antecedentes (HOBBES, 1993, p. 75). A lei é o produto do consenso de quem a fez, o que torna injusta qualquer ação contrária a ela. Afirma (HOBBES, 1993, p. 76) ainda que fazer uma lei seja criar uma "causa" de justiça; logo, a lei passa a ser um antecedente "necessário" da ação. Por outro lado, como seria possível avaliar a justiça da lei? Esse é um problema teórico que Hobbes tentou evitar ao longo de suas obras (Ver GAUTHIER, 1969; JAMES, 1969; RIBEIRO, 1984; STRAUSS, 1961; SOMMERVILLE, 1992; ZARKA, 2001), mas que enfrenta em Liberdade e Necessidade. Recorde-se o famoso aforismo que notabilizou a concepção do justo em Hobbes (1998): non veritas, sed auctoritas facit legem, ou seja, não é a verdade da coisa, mas 
a autoridade quem faz a lei. No entanto, para não se furtar de um mínimo enfrentamento a esse problema no texto de 1645, Hobbes (1993, p. 77) recorre novamente ao direito natural à manutenção da própria vida que um condenado à morte possui mesmo contra uma decisão judicial baseada na lei do Estado: o justo positivo teria sido realizado, mas o justo natural consentiria ao homem fazer tudo que lhe for possível para escapar da morte.

Outra crítica de Bramhall (1999, p. 12-13) que Hobbes precisou abordar foi acerca de como conciliar contingência e liberdade com a pré-ciência e os decretos de Deus; enquanto o bispo recorria ao "conhecimento de Deus" expressão introduzida por ele, sem maiores explicações, somente nas últimas páginas do seu texto -, Hobbes (1993, p. 103-105) afirmava desconhecer essa expressão nas Escrituras e que tal conhecimento somente teria sentido se pensado como parte da "eternidade", devendo essa ser compreendia pela "sucessão perpétua" de ações humanas e naturais; todavia, ressalta que contingência e liberdade estão nos planos materiais de domínio da ação humana, longe de qualquer recurso a argumentos transcendentes ou causas metafísicas.

Antes de encerrar seu texto, Hobbes (1993, p. 111-112) sintetiza seus argumentos tomando como referência, por um lado, o "livre arbítrio" como ponto de referência para a compreensão de conceitos como espontaneidade, deliberação, vontade, propensão e apetite, enquanto que, por outro lado, utiliza a noção de Deus como argumento derradeiro que comprovaria a plena correção lógico-racional de sua teoria das causas anteriores. Em outras palavras, Deus restaria como elemento puramente metafísico e transcendental responsável por instituir em cada indivíduo o livre arbítrio, uma vez que, no plano lógico-material, o elemento central a ordenar todos demais componentes da ação humana seria o livre arbítrio.

\section{Considerações finais}

Por mais que as controvérsias com o bispo Bramhall tenham sido centrais para a hipótese teórica sustentada nesta pesquisa, há uma série de conclusões preliminares que precisam ser recuperadas. 
A primeira e óbvia conclusão que pode ser tirada por quem tenha contato com o conceito de liberdade nas obras de Hobbes é que ele se valeu daquela palavra em uma plurivocidade de sentidos. Entretanto, ao tentar sistematizar, em Do Cidadão, de 1643, possíveis espécies de liberdade, ele parece crer que somente a análise de impedimentos externos e impedimentos arbitrários seria suficiente para dar coerência ao seu esquema conceitual. Ao falar em ausência de impedimentos como liberdade frente a impedimentos externos, já restava claro naquela obra o grau de dificuldades que enfrentaria com as causas antecedentes à ação.

Não obstante a doutrina costumeiramente faça um salto ligando diretamente duas obras referenciais no pensamento hobbesiano - Do Cidadão e Leviatã -, há um momento intermediário que rendeu frutos inesperados: a controvérsia com o bispo Bramhall. Fora esse o momento em que Hobbes conseguiu retomar com clareza a questão das causas antecedentes e fundamentar suas razões para a necessária determinação da ação.

O momento histórico em que se desenvolveu o embate teórico com o bispo Bramhall - e todas as particularidades de tal momento, como o "autoexílio" forçado de ambos, a guerra civil britânica etc. - representou uma oportunidade única para que Hobbes pudesse reconstruir a noção de livre arbítrio em seu próprio pensamento. Partindo de uma metodologia puramente analítico-descritiva ao tratar das principais obras de Hobbes acerca do tema da liberdade até chegar ao momento derradeiro de emprego de uma abordagem metodológica histórico-crítica, a pesquisa que ora se encerra tem a modesta pretensão de chamar a atenção para um trabalho do pensamento hobbesiano pouco conhecido, em comparação, por exemplo, com seu opus magnum, mas que, todavia, apresenta fortes sinais de ter sido um singular esforço intelectual de reconstrução do próprio pensamento.

Inegavelmente, no âmbito da temática relativa à liberdade, o Leviatã surgiria como o grande legado deixado por Hobbes, pois é onde ele resolve a aparente relação de conflito entre liberdade do indivíduo e liberdade do Estado, valendo-se da dicotomia proposta entre duas naturezas distintas de liberdade; a do Soberano seria plena e absoluta porque é consequ- 
ência do pacto originário que o autorizou, enquanto que a do indivíduo dependeria de previsão legal ou de ausência de vedação legal justamente porque foi sua vontade livre que, quando do estado de natureza, autorizou o Soberano a agir em seu nome e proveito. De uma aparente relação de exclusão, surge então uma causalidade lógico-racional entre ambas as liberdades, ainda que de naturezas distintas.

É exatamente esse o ponto que, durante o período de gênese do Estado moderno, desconhece autor que tenha conseguido apresentar uma proposição teórica tão ontologicamente vinculante entre indivíduo e Estado. A melhor compreensão do pensamento hobbesiano, no entanto, demanda que elementos essenciais, como as noções de determinação, necessidade, causalidade, contingência, espontaneidade, entre outras, sejam estudadas com precisão, sob pena de que um novo Hobbes, muito diferente do original, seja criado por quem o lê e sobre ele escreve, nesses quase quatro séculos que nos separam das suas principais obras.

\section{Referências}

BRAMHALL, J. Brahmall's discourse of liberty and necessity. In: CHAPPELL, V. (ed.). Hobbes and Bramhall on liberty and necessity. Cambrigde: Cambrigde University, 1999. p. 1-14. https://doi.org/10.1017/cb09781139164207.005

DESCARTES, R. Meditações metafísicas. 4. ed. Tradução de Maria Ermantina Galvão. São Paulo: Martins Fontes, 2016.

FRATESCHI, Y. Liberdade e livre-arbítrio em Hobbes. Cadernos de História e Filosofia da Ciência, Campinas, v. 17, n. 1, p. 109-124, 2007.

GAUTHIER, D. Logic of Leviathan. Oxford: Clarendon, 1969.

GOYARD-FABRE, S. Le droit et la loi dans la philosophie de Thomas Hobbes. Paris: Klincksieck, 1975.

HOBBES, T. De la liberté et de la necessité. [Tradução de] Franck Lessay. Paris: Vrin, 1993.

HOBBES, T. Dialogue between a philosopher and a student of the common law of England. Chicago: Cropsey Editor, 1998.

HOBBES, T. Do cidadão. São Paulo: Martins Fontes, 1998. 
HOBBES, T. Elementos da lei natural e política. São Paulo: Ícone, 2002.

HOBBES, T. Les questions concernant la liberté, la nécessité et le hasard: controverse avec Bramhall II. Paris: Vrin, 1999. https://doi.org/10.7202/401309ar HOBBES, T. Leviathan. London: Pelican Books, 1968.

JAMES, D. G. The life of reason: Hobbes, Locke and Bolingbroke. London: Longsman, 1969.

JOHNSTON, D. The rhetoric of Leviathan. Princeton: Princeton University, 1989.

LEIBNIZ, G. W. F. Réflexions: sur l'ouvrage que M. Hobbes a publié en anglais, de la liberté, de la necessité et du hasard. In: LEIBNIZ, G. W. F. Oeuvres de Leibniz. Paris: Charpentier, 1842. p. 319-329. https://doi.org/10.2307/j.ctv69t9vr.10 LESSAY, F. Introduction. In: HOBBES, T. De la liberté et de la necessité. [Tradução de] Franck Lessay. Paris: Vrin, 1993. p. 31-54.

Macpherson, C. B. The political theory of possessive individualism. Oxford: Clarendon, 1962.

MIRANDA, S. R. N. Bramhall e Hobbes sobre liberdade e necessidade. Fundamento, Ouro Preto, v. 2, n. 2, p. 9-40, 2011.

PENNOCK, J. R. Hobbes's confusing 'clarity': the case of liberty. The American Political Science Review, Cambridge, v. 54, n. 2, p. 428-436, 1960. https://doi. org/10.2307/1978303

Ribeiro, R. J. Ao leitor sem medo: Hobbes escrevendo contra o seu tempo. São Paulo: Brasiliense, 1984.

SABINE, G. H. A history of political theory. New York: Henry Holt, 1937.

SOMMERVILLE, J. P. Thomas Hobbes: political ideas in historical context. New York: St. Martin's, 1992. https://doi.org/10.1007/978-1-349-22131-8

STRAUSS, L. The political philosophy of Hobbes. Chicago: University of Chicago, 1961.

WHITE, S. Sovereign virtue. Los Angeles: Stanford University, 1992.

ZARKA, Y.-C. Hobbes e la pensée politique moderne. Paris: PUF, 2001. 


\section{Endereço postal}

\section{Anderson Vichinkeski Teixeira}

Universidade do Vale do Rio dos Sinos

- Campus São Leopoldo

Av. Unisinos, 950 - Bairro Cristo Rei,

São Leopoldo - RS,

CEP 93020-190 